\title{
Evaluation of pure tone audiometry and impedance screening in infant schoolchildren
}

\author{
Ian Holtby, Donald P Forster
}

\begin{abstract}
Study objective-The aims were (1) to evaluate impedance measurements against pure tone audiometry as a screening method for the detection of middle ear changes associated with hearing loss in infant school children; (2) to estimate the costs to the health authority of each method.

Design-The study involved two stage screening in which both methods were offered, pure tone audiometry being carried out by school nurses and impedance screening by a doctor.
\end{abstract}

Setting-18 infant or primary schools in Langbaurgh, Cleveland, UK.

Participants-610 previously unscreened infant school children took part in the study.

Measurements and main results-Main outcome measures were the sensitivity, specificity, and predictive value of each screening method, using clincal assessment and action as the validating technique. The sensitivity and the predictive value of a positive test in two stage impedance screening was markedly superior to that of pure tone audiometry. The specificity was similar using the two methods. In addition the impedance method was more rapid and estimated to consume less resource as a screening procedure than pure tone audiometry.

Conclusions-The superiority of the use of impedance screening established in this study should be confirmed in a subsequent audit carried out purely by school nurses.

South Tees Health

Authority, Poole

Hospital,

Middlesbrough, Cleveland TS7 0NJ, United Kingdom.

I Holtby

Department of Community Medicine, University of Newcastle upon Tyne Medical School, Newcastle upon Tyne, United Kingdom. D P Forster

Correspondence to: Dr Holtby

Accepted for publication January 1991
The theory underlying the early detection of hearing loss is that, following appropriate intervention, the development of normal speech and language skills may ensue. ${ }^{1}$ Typically the minimum screening undertaken is a test by the health visitor when the child is seven to nine months old and a further check shortly after school entrance. This latter screening test usually involves the use of sweep or pure tone audiometry and is carried out by a nurse in the school. ${ }^{2}$ An alternative method is impedance screening which measures the resistance to sound by the middle ear and its contents rather than hearing impairment per se. ${ }^{3}$ The impedance method is used routinely in screening for hearing loss in schools by only $4 \%$ of district health authorities. ${ }^{2}$

The purpose of the present study was to carry out an audit of the established system of pure tone audiometry screening for hearing loss in infant schoolchildren in one district health authority. In a practical setting, the effectiveness of pure tone audiometry was compared with that of the impedance method.

\section{Methods}

Six year old schoolchildren in 18 infant schools were the potential entrants to the study. However, children already known by the school nursing service to have middle ear disorders were excluded from further study. The schools were randomly allocated into groups $\mathbf{A}$ and $\mathbf{B}$. Following permission from parents, children in group A were first screened at school by the pure tone audiometry method and then by the impedance technique within a period of five days. Children in group B were screened in reverse order.

The pure tone audiometry tests were carried out by nine different nurses who adopted the usual district guidelines for assessment. Hence any child who was unable to hear pure tones of 20 decibels intensity in either ear in the range of frequencies 0.25 to $8 \mathrm{kHz}$ was considered to have failed the test. All impedance tests were carried out by one community child health doctor at the relevant school. It was possible for children to fail the impedance test on any one of three criteria, namely a tympanic pressure reading of $-150 \mathrm{~mm}$ water or greater negative pressure; the inability to demonstrate a compliance curve or the achievement of one with very low amplitude (less than $0.2 \mathrm{ml}$ ); or the inability to demonstrate a stapedial reflex. The time taken for each of these screening sessions was recorded. The results of the alternative method were not known to the respective operators. All screening took place between February and July, 1988.

Children who failed either of these stage 1 screening tests were rescreened. This stage 2 screening took place at the school after an interval of six weeks, thus allowing time for transient middle ear conditions to resolve. Children were only rescreened using the method by which they had failed at stage 1 . If they had failed using both methods at stage 1 , these were used in reverse order at stage 2 screening.

Those children failing stage 2 screening on either method were referred to an aural clinic for examination under standardised conditions. Otoscopic examination was carried out by an independent assessor (a senior clinical medical officer with special training in audiological techniques). Pure tone audiometry was carried out in a soundproof room and this was followed by the use of the impedance technique when there was any doubt as to the presence of middle ear pathology. Some screened children reached expert assessment via another route in that they 
had been referred by their general practitioner in the meantime to an ENT consultant. The results of these consultant examinations have been included with those of the independent assessor.

The results of the examinations by the independent assessor and ENT consultants were used as the reference standard against which the prior screening tests were judged. Those children who had normal hearing on pure tone audiometry testing, ie, who were able to hear pure tones of at least 20 decibels or less in both ears at all frequencies, and who had normal otoscopic examination or an unimportant abnormality with no implications for treatment, were discharged. However, in the practical setting of this study, a child with normal clinical findings could occasionally be put foward for further review in the presence, for example, of parental concern. Those with a hearing loss in either ear and/or an abnormality on otoscopy, or evidence on impedance testing of a middle ear effusion or other abnormalities which had implications for treatment were either seen again for review or were referred for surgery. Following the interim clinical judgements of normal, probably normal, and abnormal, the outcome for the child, after these investigations, was placed in one of three

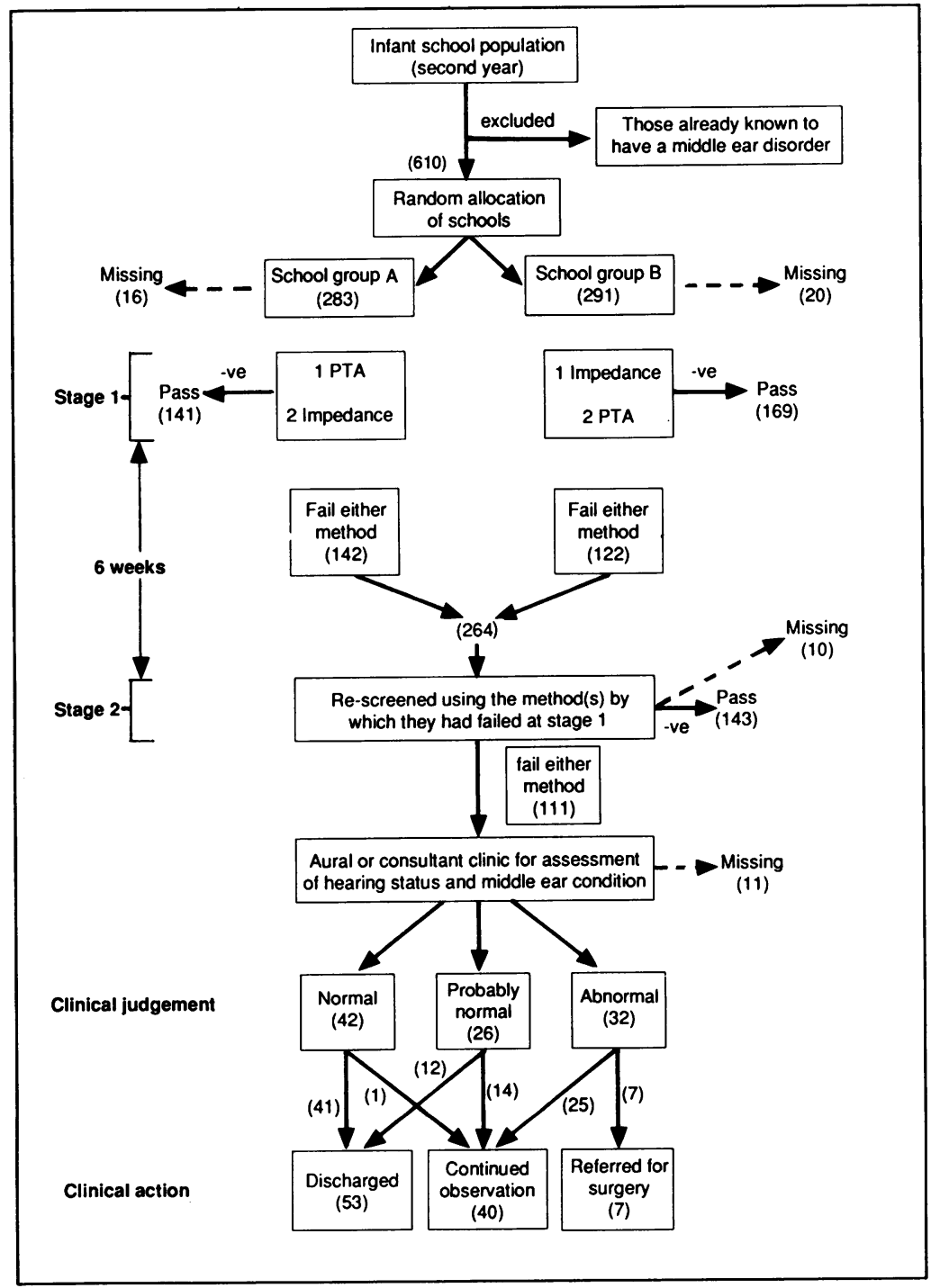

Schematic representation of the screening procedure. PTA = pure tone audiometry categories: discharged as negative; continued observation as a positive; or referral as a positive for surgery. All aural clinic records were checked from the time of stage 1 screening to February, 1990 (a minimum follow up period of 18 months), not only to follow up those screened as positive but to ensure that children initially screened as negative did not reach the clinic by some other route, ie, to identify any children originally screened as false negatives. Similarly, children in the study group who missed screening but subsequently reached the aural clinic would be detected. The costs of the two methods at 1988 prices were assessed using the formula proposed by Cooper et al. ${ }^{4}$

\section{Results}

The potential entrants to the study were 610 schoolchildren in infant schools, those already known to health services to have a middle ear disorder having been excluded. Of these children, $574(94 \cdot 1 \%)$ were screened by both methods at stage 1, 283 in school group A and 291 in school group $B$.

At stage 1 screening, 99 children $(17 \cdot 2 \%)$ failed in both methods, $73(12.7 \%)$ on pure tone audiometry alone, and $92(16.0 \%)$ on impedance screening alone. The repeatability between the methods at stage 1 was $37.5 \%$. Two hundred and sixty four children passed to the second stage of screening, of whom 99 were scheduled for rescreening using both methods at stage 2 (table I). Rescreening by both methods was achieved in $94(94.9 \%)$ and repeatability between the methods at this stage increased to $67.6 \%$.

Table I Comparability of methods at stage 1 screening (restricted to those children who received both screening methods at stage 1)

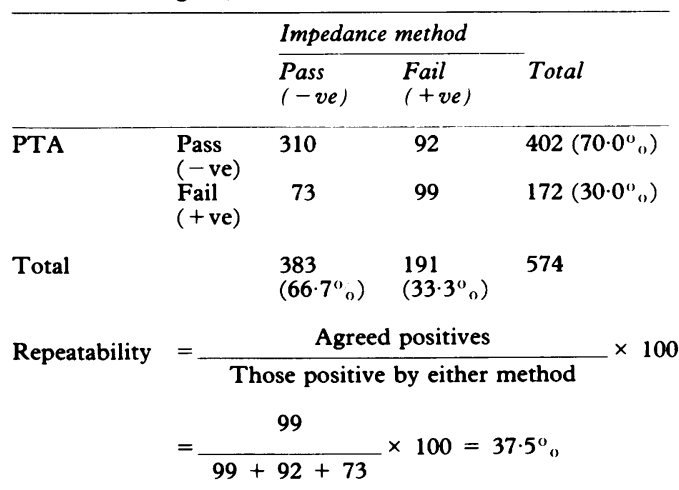

Tables II and III set out the progress of children through the two stage screening process. Seventy five children were positive for two stage pure tone audiometry and 82 positive for two stage impedance. Forty six of these children were positive to both two stage methods, 29 failed pure tone audiometry only, and 36 failed impedance only. Hence, 111 children (see figure) failed either method. The validity of one stage and two stage screening for each method was evaluated by comparing the results of screening with the subsequent clinical actions taken. For this purpose, true positives were designated as those children referred for surgery or a combination of the categories referred for surgery and continued observation. Each of the seven cases referred for surgery actually underwent surgery, yet two of 
these were negative to two stage pure tone audiometry screening, having been identified through the impedance screening route.

The measures of validity are set out in table IV. Using stage 1 screening alone, the specificities and the predictive values of a positive test using each screening method are broadly similar. However, the sensitivity of the stage 1 impedance test is superior to that for pure tone audiometry, regardless of whether a true positive is defined solely as a referral for surgery or a combination of referral for surgery and continued observation. When two stage screening is evaluated, the sensitivities fall from those of stage 1 alone, more so for pure tone audiometry than for impedance screening. The values for two stage specificities are better than the one stage values. With respect to the predictive values for a positive test, these increase for pure tone audiometry tests and approximately double for impedance between stage 1 screening alone and two stage screening. This is to be expected since the predictive value of a positive test is directly associated with the prevalence of the condition under scrutiny. ${ }^{5}$ When the second stage of screening is introduced into the analysis, the prevalence of hearing loss (or conditions which may give rise to it) has effectively been increased because of the elimination from further screening of negatives (mainly true negatives) at stage 1 .

One child, absent for screening in this study, was subsequently assessed clinically at the aural clinic. She was placed in the continued

Table II Validity of pure tone audiometry (PTA) screening

\begin{tabular}{|c|c|c|c|c|c|}
\hline & \multicolumn{3}{|c|}{ Clinical action } & \multirow[b]{2}{*}{ Missing } & \multirow[b]{2}{*}{ Tota } \\
\hline & Discharge & $\begin{array}{l}\text { Continued } \\
\text { observation }\end{array}$ & Surgery & & \\
\hline $\begin{array}{l}\text { Negative at stage } 1 \\
\text { PTA }\end{array}$ & 392 & 9 & 1 & 0 & 402 \\
\hline $\begin{array}{l}\text { Positive at stage } 1 \\
\text { PTA and negative at } \\
\text { stage } 2 \text { PTA }\end{array}$ & 82 & 7 & 1 & 0 & 90 \\
\hline $\begin{array}{l}\text { Positive at both stage } 1 \\
\text { and stage } 2 \text { PTA }\end{array}$ & 39 & 24 & 4 & 8 & 75 \\
\hline Total & 513 & 40 & 6 & 8 & 567 \\
\hline
\end{tabular}

Note

(1) Of 574 children screened at stage 1 , seven have been omitted from the table: one child failed stage 1 PTA and impedance tests, missed stage 2 PTA screening, failed stage 2 impedance screening and was subsequently referred for surgery; six children failed stage 1 PTA but did not attend for stage 2 PTA.

(2) Children screened as negative were recorded as true negatives (discharges)-see text.

(3) True positives were those children referred for surgery or designated for continued observation.

Table III Validity of impedance screening

\begin{tabular}{|c|c|c|c|c|c|}
\hline & \multicolumn{3}{|c|}{ Clinical action } & \multirow[b]{2}{*}{ Missing } & \multirow[b]{2}{*}{ Total } \\
\hline & Discharge & $\begin{array}{l}\text { Continued } \\
\text { observation }\end{array}$ & Surgery & & \\
\hline $\begin{array}{l}\text { Negative at stage } 1 \\
\text { Impedance }\end{array}$ & 380 & 3 & 0 & 0 & 383 \\
\hline $\begin{array}{l}\text { Positive at stage } 1 \\
\text { impedance and negative } \\
\text { at stage } 2 \\
\text { Impedance }\end{array}$ & 98 & 3 & 0 & 0 & 101 \\
\hline $\begin{array}{l}\text { Positive at both stage } 1 \\
\text { and stage } 2 \\
\text { impedance }\end{array}$ & 33 & 34 & 7 & 8 & 82 \\
\hline Total & 511 & 40 & 7 & 8 & 566 \\
\hline
\end{tabular}

(1) Of 574 children screened at stage 1, eight have been omitted from the above table: one child failed stage 1 impedance and PTA screening, missed stage 2 impedance, failed stage 2 PTA, and was assessed as probably normal and discharged; seven children failed stage 1 impedance screening but did not attend for the stage 2 impedance test.

(2) Children screened as negative were recorded as true negatives (discharges)-see text.

(3) True positives were those children referred for surgery or designated for continued observation. observation category but excluded from the analysis. One child, after being screened as a positive, was judged to be normal after clinical examination. In the practical setting of this study, this child was placed in the continued observation category because of parental concern.

The cost of each of the routine screening procedures was assessed at 1988 prices. Calculation of the costs has assumed the standard practice of initial screening with rescreening of positives about six weeks later. True positives, correctly identified by screening, were defined as before, namely those children who required referral for surgery alone or continued observation. It has been further inferred that both types of screening tests could be performed by school nurses. The calculations are on the basis of a typical annual intake of 1886 new infant schoolchildren in the relevant catchment area.

$\begin{aligned} & \text { Cost per child } \\ & \text { screened per } \\ & \text { instrument }\end{aligned}$
S

where $S=$ salary per hour $(£)$ of the person performing the screening test (school nurses, mid-point of scale); $\mathbf{R}=$ number of children screened per hour (including rescreening of positives); $C=$ cost of equipment $(£) ; M=$ annual maintenance cost $(£) ; L=$ lifetime of the equipment in years; and, $\mathrm{N}=$ number of children screened per instrument (audiometer/ typanometer) per year.

A striking finding was the increased screening rate possible using the impedance method: $\mathbf{4 2 \cdot 4}$ children per hour compared to $9 \cdot 3$ per hour with pure tone audiometry (table V). Within the catchment area, 14 audiometers are currently used by school nurses for pure tone audiometry. If a similar number of impedance tympanometers were required for children in the same catchment area, the cost per true positive identified per instrument was similar for both methods. Given the difference in screening rates, however, it is probable that only three impedance tympanometers would be required for the annual testing of new infant schoolchildren in the catchment area; in which case, the cost per child screened or true positive identified per instrument by the impedance method is markedly lower.

\section{Discussion}

The results of this audit indicate that, whichever method is used, there are benefits in a two stage screening procedure with an interval of approximately six weeks, since the specificity (the ability to avoid false positives) and predictive values are improved. Moreover, using the impedance method, there is little loss in sensitivity when a two stage screening is undertaken compared to stage 1 alone. Assessing the two methods after two stage screening shows that the sensitivity (the ability to avoid false negatives) and the predictive value are superior for the impedance method compared to pure tone audiometry.

A number of caveats concerning the practical setting of the study should, however, be taken into 
account in drawing conclusions. Firstly, the impedance screening tests were carried out by one medically qualified operator whereas the pure tone audiometry method was undertaken by nine school nurses, thus providing the opportunity for observer variation. In other contexts, however, nurses have been trained in the impedance method and have found it to be acceptable both to themselves and to the children involved. ${ }^{6}$ Secondly, it was not possible, in practice, to examine clinically and test in sound proof conditions all children entering the study. However, the records of the aural clinic were searched continually to identify the names of any of the 610 entrants to the study. By this method, all children who, through screening or otherwise, had reached the aural clinic could be identified. Thirdly, even when full clinical assessment, including measurements in the standardised conditions of an aural clinic takes place, some uncertainty remains with respect to whether an important abnormality exists and the appropriate action to be taken. For the purposes of this audit, we included in the validating clinical decisions not only referral for surgery but also the decision to continue clinical observation. This was because the latter category clearly represented genuine clinical concern and it is arguable that any screening test should identify children within such a category. For those referred for surgery, evidence is emerging from randomised controlled interventions that significant short term improvements in hearing can be obtained in severe cases. ${ }^{78}$ Notwithstanding these caveats, very few health districts in the past have collected data which would allow even the most basic assessment of their screening programmes. ${ }^{2}$

The costings take into account only the major components of cost to the NHS, namely salary and instrument costs. The negligible costs of consumables associated with either instrument and the travelling costs of the testers have been omitted. Moreover, we only considered the costs to the NHS and not those that may occur to the parents or schools, and an assumption was made that school nurses could carry out the impedance technique with effectiveness and rapidity similar to the doctor in this study. The higher screening rate for the impedance technique would also release the time of the testers, probably school nurses, for other effective procedures in addition to reducing the number of instruments required.

Given the fact that the two stage impedance screening method compared to pure tone audiometry has higher sensitivity, predictive value, and screening rates, why is it not the method of usual choice? ${ }^{2}$ One criticism of impedance measurements is that they do not test directly for hearing loss but for the integrity of the mechanics of the middle ear mechanism. ${ }^{9}$ Nevertheless, disorders of the middle ear may ultimately lead to established hearing loss. ${ }^{10}$ The cost advantages of the impedance method depend on the impedance technique being used by school nurses, combined with the efficient management of the school nurse service. Clearly an acceptance of the alternative technique by, and a training programme for, school nurses will be necessary. An important issue is that, although pure tone audiometry requires the cooperation of the child and this can be a problem, the impedance method is rapid and mechanical, thus giving little time for establishing rapport with the child. In the management of successful change, it is these behavioural aspects, such as job satisfaction and acceptability to children, that require attention, in addition to technical change. ${ }^{1112}$ Hence, in impedance screening, it must be considered
Table IV Evaluation of the validity of the screening tests based on
values in tables II and III

\begin{tabular}{|c|c|c|c|c|c|c|}
\hline & \multicolumn{2}{|c|}{ Sensitivity $\left({ }^{o}\right)$} & \multicolumn{2}{|c|}{ Specificity $\left({ }^{o}{ }_{0}\right)$} & \multicolumn{2}{|c|}{$\begin{array}{l}\text { Predictive value } \\
\text { of a positive test }\left({ }^{\circ}{ }_{0}\right)\end{array}$} \\
\hline & $A^{\mathrm{a}}$ & $B^{\mathrm{b}}$ & $A$ & $B$ & $A$ & $B$ \\
\hline $\begin{array}{l}\text { Stage } 1 \text { alone } \\
\text { PTA } \\
\text { Impedance }\end{array}$ & $\begin{array}{l}78 \cdot 3 \\
93 \cdot 6\end{array}$ & $\begin{array}{r}83 \cdot 3 \\
100 \cdot 0\end{array}$ & $\begin{array}{l}76 \cdot 4 \\
74 \cdot 4\end{array}$ & $\begin{array}{l}72 \cdot 5 \\
69 \cdot 3\end{array}$ & $\begin{array}{l}21 \cdot 8 \\
25 \cdot 7\end{array}$ & $\begin{array}{l}3 \cdot 0 \\
3 \cdot 8\end{array}$ \\
\hline $\begin{array}{l}\text { Two stage } \\
\text { PTA } \\
\text { Impedance }\end{array}$ & $\begin{array}{l}60 \cdot 7 \\
87 \cdot 2\end{array}$ & $\begin{array}{r}66 \cdot 7 \\
100 \cdot 0\end{array}$ & $\begin{array}{l}92 \cdot 4 \\
93 \cdot 5\end{array}$ & $\begin{array}{l}88 \cdot 6 \\
87 \cdot 5\end{array}$ & $\begin{array}{l}37 \cdot 3 \\
50 \cdot 0 \\
\end{array}$ & $\begin{array}{l}5 \cdot 3 \\
8 \cdot 5 \\
\end{array}$ \\
\hline
\end{tabular}

${ }^{\mathrm{a}} \mathrm{A}=$ validity measures based on a true positive being a child ultimately being referred for surgery or designated for continued

${ }^{b} \mathbf{B}=$ Validity measures based on a positive being a child ultimately being referred for surgery only.

Table V Costs of screening in the catchment area

\begin{tabular}{|c|c|c|c|c|}
\hline & \multirow{2}{*}{$\begin{array}{r}\begin{array}{c}\text { Calculation of cost per } \\
\text { child screened per } \\
\text { instrument }\end{array} \\
\frac{S}{R}+\frac{C+(M \times L)}{(N \times L)}\end{array}$} & \multirow{2}{*}{$\begin{array}{l}\text { Cost per child } \\
\text { screened per } \\
\text { instrument }\end{array}$} & \multicolumn{2}{|c|}{$\begin{array}{l}\text { Cost per true positive } \\
\text { correctly identified } \\
\text { per instrument }\end{array}$} \\
\hline & & & $A^{\mathrm{a}}$ & $B^{\mathrm{b}}$ \\
\hline $\begin{array}{l}\text { PTA (using } 14 \\
\text { (audiometers) }\end{array}$ & $\frac{5.99}{7 \cdot 3}+\frac{775=(45 \times 10)}{(135 \times 10)}$ & $£ 1.73$ & $£ 35.47$ & $£ 248.26$ \\
\hline $\begin{array}{l}\text { Impedance: } \\
\text { (using 1 } \\
\text { tympanometer) } \\
\text { (using } 14 \\
\text { tympanometers) } \\
\text { (using 3 } \\
\text { tympanometers) }\end{array}$ & $\begin{array}{l}\frac{5.99}{42 \cdot 4}+\frac{3195+(70 \times 10)}{(1886 \times 10)} \\
\frac{5.99}{42 \cdot 4}+\frac{3195+(70 \times 10)}{(135 \times 10)} \\
\frac{5.99}{42.4}+\frac{3195+(70 \times 10)}{(629 \times 10)}\end{array}$ & $\begin{array}{l}£ 0.35 \\
£ 3.03 \\
£ 0.76\end{array}$ & $\begin{array}{r}£ 4.90 \\
£ 42 \cdot 42 \\
£ 10.64\end{array}$ & $\begin{array}{r}£ 28 \cdot 70 \\
£ 248 \cdot 46 \\
£ 62 \cdot 32\end{array}$ \\
\hline
\end{tabular}

${ }^{a} A=a$ true positive defined as a child ultimately referred for surgery or designated for continued observation

${ }_{\mathrm{a}} \mathrm{A}=\mathrm{a}$ true positive defined as a child ultimately referred for surgery or $\mathrm{des}$
$\mathrm{b}_{\mathrm{B}}=\mathrm{a}$ true positive defined as a child ultimately referred for surgery only

$\mathrm{b}=\mathrm{a}$ true positive defined as
$\mathrm{PTA}=$ pure tone audiometry

PTA = pure tone audiometry

Note: 14 audiometers are currently used in the catchment area in question. On the basis of the ratio of the screening rates per hour for PTA and impedance, $7 \cdot 3$ to $42 \cdot 4$, only three tympanometers would be required 
whether an opportunity for informal enquiry by school nurses about other current problems and health promotion is being lost due to the reduced time and rather mechanical method. In this paper, we have focused on the $\mathbf{5 7 4}$ children who received screening by both methods at stage 1 and passed through the other later procedures. In addition however, the figure illustrates the numbers of children missing a procedure at each phase, one of whom was subsequently shown to have abnormal findings and to require continued observation. In practice, the proportion of children missing routine procedures is of a degree that requires an effective system for recontact.

Given the findings of this evaluation, we recommend to professionals involved in child health screening services that in the first instance training programmes in the use of impedance tympanometers by school nurses should be arranged. A futher audit should then be carried out to test the validity and efficiency of pure tone audiometry against that of the impedance method, both techniques being carried out by school nurses. If the results presented here are confirmed, the motivation and impetus for the completion of change will be present.
We are very grateful to $\mathrm{Dr} U$ Kumar for clinical assessments, to Dr S Jarvis, Dr P Pearson, and Mr L Flood for advice, and to Karen Cowley for secretarial assistance.

1 Hall DMB, ed. Health for all children: a programme for child health surveillance. Oxford: Oxford University Press, 1989 60

2 Stewart-Brown S, Haslum MN, Screening for hearing loss in childhood: a study of national practice. $B M F 1987 ; 294$ 1386-8.

3 Ferrer HP, Use of impedance audiometry in schoolchildren Public Health 1974; 88: 153-63.

4 Cooper JC, Gates GA, Owen JH, Dickson HD. An abbreviated impedance bridge technique for school screening. I Speech Hearing Disord 1975; 40: 260-9.

5 Barker DJP, Rose G, Epidemiology in medical practice. Edingburgh: Churchill Livingstone, 1984: 128.

6 Bonny IC. Five years experience of combined impedance and audiometric screening at school entry. Public Health 1989; 103: 427-31.

7 Black NA, Sanderson CFB, Freeland MP. A randomised controlled trial of surgery for glue ear. $B M \mathcal{F} 1990 ; 300$ : $1551-6$.

8 Otitis media with effusion in children. Lancet 1990; 336 23-4.

9 Fisch L. Development of school screening audiometry. $B r f$ Audiol 1981; 15: 87-95.

10 Maw A R secretory otitis media in childhood. Br Med Bull 1987; 43: 950-65.

11 Hollander $\mathrm{H}$, Hazewinkel $\mathrm{A}$, Leliefeld $\mathrm{H}$. Health management training: a workbook for course organisers. Dusseldorf: Association of Schools of Public Health in the European Region, 1987 (Mimeo)

12 Forster DP, Hadley R. The NHS reforms: conditions fo successful change. Health Serv Manage 1989; 85: 215-18. 